\title{
The Empirical Research on an Instruction Model for Promoting Understanding Supported by Information Technology
}

\author{
Wenjuan Lu \\ Guangdong Open University, Guangzhou, 510091, China
}

\begin{abstract}
To solve the problem that students do not understand what they learn, and to improve the effect of teaching, the author constructs an instruction model for promoting understanding supported by information technology. To test the instruction model, the author designs and carries out a study which is a learner-centered comprehensive practical activity outside classroom. It makes probability and statistics of mathematics in 5th grades of primary school the theme, and takes the instruction model as the core, to design the study so as to explore the effect of the instruction model on promoting understanding finally.
\end{abstract}

Keywords-information technology; understanding; instruction model.

\section{INTRODUCTION}

Students' not understanding what they learn has been very common and long-existed in teaching. Understanding takes a significant effect on improving learning and teaching. Once understood, students will get further improvement on knowledge mastering and memory, and burden of learning will reduce greatly. Learning will become much simpler and easier, and students will get better efficiency and grades.

At present, researches concerned on promoting understanding focus on: (1)TfU instruction model which is "teaching for understanding". It designs, modifies and audits curriculum and teaching to help learners enhance understanding. There are four interacting components in this TfU model: inspirational topics, targets, activities and ongoing evaluation[1]. (2)Strategies, methods or teaching designs related to understanding. For example, cooperative learning and the promotion of understanding[2], and the design to improve understanding[3]. (3)The discussion on understanding, for example, the discussion about dimensions of understanding[4], the process and obstacles of understanding, and so on. These studies explain issues related to understanding from different angles. But, some of them lack of information technology, some focus on theoretical discussion, some have not formed kinds of teaching model, and others have not experimental verification. Information technology can provide more optimal means and methods to help students understand and make them study better. Thus, the author constructs an instruction model promoting understanding supported by information technology to help students understand what they learn better[5].

\section{THE INTRODUCTION OF THE INSTRUCTION MODEL PROMOTING UNDERSTANDING SUPPORTED BY INFORMATION TECHNOLOGY}

On the base of research and discussion, the author thinks that there are several major factors which have an important impact on teaching promoting understanding including: information technology, effective strategies and methods, meaningful teaching tasks and activities, good organization of teaching tasks and activities, tools(for students and teachers), cooperation and discussion, and so on. Then, it builds an instruction model which promotes understanding supported by information technology, as shown in Figure 1[5].

In this model, information technology is a strong support for teaching to promote understanding. Computers and networks can collect large amounts of information on successful learning and difficult learning. They can significantly contribute to scientific learning as a powerful tool for promoting understanding of science[6]. Effective strategies and methods can provide a flexible scaffold, and can bridge knowledge and understanding for students. Meaningful teaching tasks and activities are the base and prerequisite of learning and understanding. Good organization of teaching tasks and activities is an important guarantee for teaching and studying. There are various tools used in teaching, and they can make abstract problems visualized and specific, with assisting and motivating understanding. Cooperation and discussion play an invaluable role on knowledge sharing, ideas meeting, thinking inspiration, and structural changes and knowledge reorganization in brain to get understanding finally[5]. 


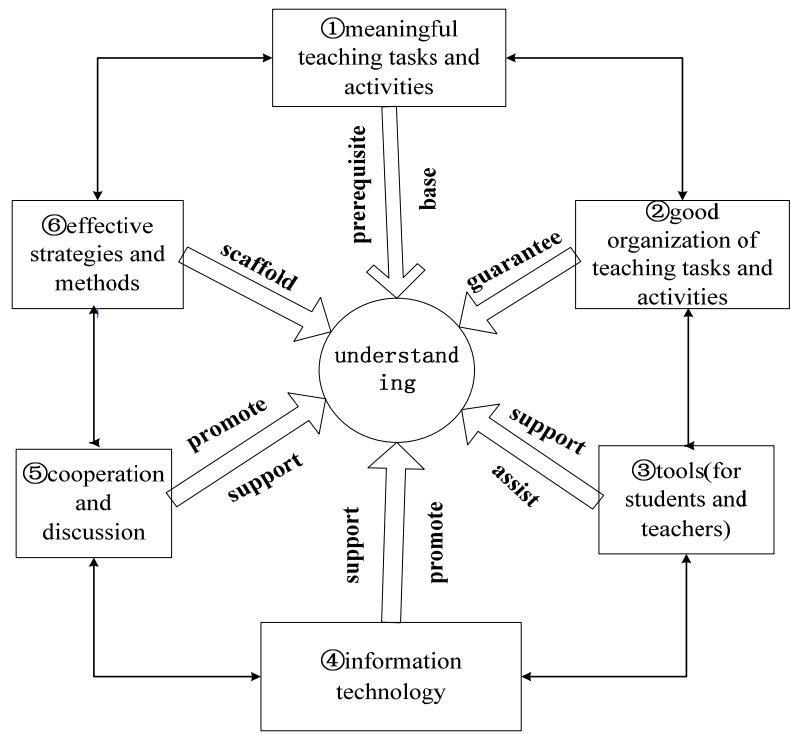

Figure1. The instruction model built to promote understanding supported by information technology

III. THE EMPIRICAL RESEARCH ON THE INSTRUCTION MODEL FOR PROMOTING UNDERSTANDING SUPPORTED BY INFORMATION TECHNOLOGY

In order to test the effect of this instruction model, the author tries to design and carry out a study which is a learner-centered comprehensive practical activity outside classroom. It makes probability and statistics of mathematics in $5^{\text {th }}$ grades of primary school the theme, and takes the instruction model as the core, to explore the effect of the instruction model on promoting understanding finally.

\section{A. Study}

The learner-centered comprehensive practical activity is "Water with Our Lives". It is one of those integrated practical activities in the second phase of the project "Child-Friendly Schools in My Mind" in China and UNICEF "Sister School” Project. With combining what they have learned and their lives closely, the study mainly asks students to integrate their mathematical knowledge, skills and thinking, and use them flexibly to solve real problems, so as to explore the effect that the instruction model plays on students' understanding.

\section{B. Design}

The study used a single group before-posttest quasiexperimental design. The score of before-test was Y0, the intervention was $\mathrm{X} 0$, the score of post-test was $\mathrm{Y}$, then the result was $\mathrm{C}=\mathrm{Y}-\mathrm{Y} 0$. We would carry it out with questionnaires to get data.

\section{Participants}

The participants were 95 students studying in six different primary schools from Guangxi Province, Sichuan Province, Chongqing, Gansu Province, and Guangdong Province. They all participated in the second phase of the project "Child-Friendly Schools in My Mind" in China and UNICEF "Sister School” Project.

\section{Procedure}

This study based on distant cooperative learning projects in China and UNICEF "Sister School" Project. According to the project, the participant schools must be combined into one-one or one-two teams, thus they could carry out those practical activities with each other.

Before the activities, we would take a questionnaire survey to all participant students to test their knowledge level. Then, these students would be assigned to different groups. There were four or five students in each team. Instructors assigned tasks to every group and asked students to participate into designing activities.

In the first week, students involved in learning to use computer, network, newspapers and other ways to find all information they needed to answer the questions following:

- How much water does the earth left in recent 10 years?

- How does water come into being?

- What habits or aspects do need water in our lives? Which one needs most? Which one least?

- Are there any behaviors around us that waste water?

water?

How can we do to avoid and prevent wasting

- If we save a drip of water each day for everyone, then how much water can we save in 100 years for our 1.3 billion people? ......

These interscholastic team members cooperated with each other and made friends quickly. They made records, discussed and exchange their ideas on a specified network platform (ISNet platform).

In the second week, they mainly worked to data measuring, processing and computing. They actively tried to collaborate together and communicate online. The task of third week was to make a summary and exchange feels online. Team members first made their personal summary. Then every team summed up and introspected, and they put the summaries and feelings online. Students communicated with each other within one-one or one-two interscholastic teams. The fourth week was to evaluate each other and introspect. Each team evaluated themselves and the other. They discussed with their interscholastic friends online. They could also evaluate other interscholastic teams' achievements and gave their comments online. At last, all participants would finish a questionnaire for post-test.

\section{E. Discussion}

There were both 95 copies in each questionnaire. All of them were valid which illustrated that all students finished the surveys seriously. From the data, most of the participants were in $4^{\text {th }}$ and $5^{\text {th }}$ grades, and aged between 10 to 12 years old. In this phase, the perception of children was mainly characterized by gradually learning to think from others, they could come to accept some 
different opinions to fix their own views. Their logical thinking, reasoning ability and analytical skills got enhancement, perception and memory capacity were in good time of mastering, and imagination and creativity ability improved quickly. But abstract thinking and imagination ability hadn't developed so well. They were very interested in and easy attracted to games, video animations, images, music, materials and tools that were visuilized and corourful. Children in this age were active, lively, sprightly, and full of strong curiosity and thirsty for knowledge.

\section{F. Data Analysis and Results}

According to the survey results, most of the students could understand the meanings of simple tables and diagrams before the study. They learned some about data collection and collation, how to get the average and to make statistical tables, and so on. But there were fewer students learned mode, median, three kinds of charts making, and judgments making, less than 50\%. Most students had learned part of probability and statistics. And the knowledge was considered active and fun, not so complex and easy to understand by students.

We could get two samples from the two questionnaires, and take a t test by SPSS software. The result was shown in Figure 2.From the Figure 2, $\mathrm{t}=-2.952$, significance probability(bilateral) was 0.004 , so unilateral significant probability $\mathrm{P}=0.002$. Due to the significant probability was less than 0.01 , so it could be considered that the posttest scores were significantly higher than the pretest scores [7]. Therefore, $\mathrm{P}=0.002, \mathrm{P}<0.01$, the intervention effect was significant in this study $(\mathrm{t}=-2.952, \mathrm{P}<0.01)$.

Paired Samples Test

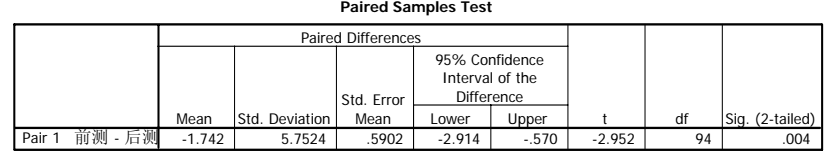

Figure 2. The result of t test in the study

\section{CONCLUSIONS}

According to above results, we concluded that the students in this study had a great improvement on understanding and application of probability and statistics, and their ability to solve problems related had made great progress. So, the study with the instruction model promoting understanding supported by information technology as the core was successful, and the model had a great effect on promoting understanding.

The range of this study is small, but the result is worthy. It is not an overnight thing that can be done to help students overcome the problem that they don't understand what they learn. We need to study and explore further and find more valuable information so as to help students and improve teaching quality. Further research about promoting understanding for students will be carried out in next few years. And we will keep on working hard for students and teaching.

\section{REFERENCES}

[1] Lu Yan. The connotation of TfU teaching model and its application in teaching. Journal of Science and Technology Information, 29, 2008.

[2] Lin Wenxiao, \& Wang Jiahua. Cooperative learning and understanding promotion. Journal of Shenyang Teachers College (Natural Science Edition), 1, 2001.

[3] Li Funing, \& Zhong zhixian. The instructional design to explore understanding promotion. Journal of Jiangxi Radio \& TV University, 2, 2012.

[4] He Ye, \& Sheng Qunli. The exploration of the dimensions of understanding. Open Education Research, 3, 2006.

[5] Lu Wenjuan. The Construction of an Instruction Model for Promoting Understanding Supported by Information Technology. Modern Educational Technology,10, 2012.

[6] Joel J.M. . Computer is a powerful tool for understanding science. Science teaching of promoting understanding--a view of the constructive approach (pp. 230). Taipei: Psychology Press,2002.

[7] Wen Zhonglin. Psychology and Education Statistics. Guangzhou: Guangdong Higher Education Press, 2006. 